\title{
Designing a Periodical Collection with the Patron in Mind: Serials and Users at the University of Michigan's Hatcher Library
}

\author{
Robert L. Houbeck, Jr.
}

Several years ago when the University of Michigan Library merged a technical service and a public service serials unit into a single body, our goals were to eliminate duplication of recording, realize a net gain in reader space, and improve serials service to our patrons. ${ }^{1}$ The first two goals we accomplished immediately. But what about patron service? How did we plan to improve patron service? And did we?

Located within the library's Technical Services Department and called Serials Services and Records (SSR), the new unit had two major functions: to maintain the Hatcher Graduate Library's serials collection and to receive and record all University Library serials. As the name of the new unit implies, we sought to improve patron access both to the serials in our collections and to information about those serials. We focused on four major endeavors.

\section{Shelving Current Issues by Call Number}

Before the merger, the technical services serials unit received and recorded Hatcher serials and forwarded the unbound issues to the public services unit. That unit then re-recorded those serials in its files, assigned each a "fixed-location" number, and shelved the issues in its unbound collection to await binding. The "fixed-location" number comprised a letter, which corresponded to a broad LC class $(B=$ philosophy, psychology, religion; $H$ = social sciences; etc.), and a number, which was essentially an accession number. As new titles were added to the collection, their urbound issues were shelved at the end of the appropriate section. When they were bound, of course, they were shelved 
in the stacks under their LC call numbers.

This system of shelving unbound issues did minimize the management difficulties of the current periodicals collection. It served patrons, though, rather less well. "Fixed-location" numbers did not appear on the cards in the public catalog. Hence, patrons looking for current issues of a serial had to look up the title a second time in the title catalog in the current serials unit. Unless a patron consulted the same title frequently and remembered its specific shelf location, he or she had to look up the title each time. The fixedlocation scheme, too, made browsing current serials impractical, since like titles were not shelved together.

By rearranging the unbound periodical collection into call number order, patron access to serials improved markedly. Patrons could now easily browse by subject. No longer needing to deal with two distinct numbering schemes for the same title, they could move more easily between the bound and the unbound sections of the Hatcher collection. Since SSR staff members were able to relabel and shift the entire collection of six thousand titles over a weekend between semesters, patrons were not inconvenienced at all.

During the merger, the project staffs of the two units had debated rearranging the unbound collection by title. Given the large number of titles and the high percentage of serials in foreign languages and with corporate body main entries, staff members concluded that call number arrangement would actually render the collection more accessible to patrons than arrangement by title. Subject arrangement, too, has enabled faculty to browse more efficiently through the latest issues of titles in their discipline.

\section{Defining "Unbound Periodical Collection" More Sharply}

A second strategy implemented was to remove from the unbound collection all materials received annually or less frequently. Several hundred annuals and irregular serials were transferred to the stacks. SSR thus became truly a collection of unbound periodicals, a concept much easier for reference staff to explain to patrons and much easier for patrons to grasp.

\section{Concentrating Serial Records and Expertise}

Before the merger, serial records for many Hatcher titles and all titles located in divisional libraries were available only in the files of the technical services serial records unit. That unit was closed to the public on evenings and weekends. The unit was also quite distant from the library's main service points: reference, public catalog information, microforms, and stacks maintenance.

The new SSR unit was located on one wing of the Hatcher Library's main service floor. Open to the public at all hours when the library is open, the unit was designed expressly to locate serial files, online and manual, near the service desk. Full-time personnel are available in the unit to help patrons until 9:00 p.m. Adjacent to the unit is the Serials Acquisitions Department. Newly received materials and new, uncataloged titles that are awaiting processing thus have been readily accessible to patrons. SSR staff members also have an RLIN terminal and an Innovacq (our local acquisition system) terminal at the service desk to provide patrons with quick access to cataloged and on-order materials.

Integrating the SSR Unit into Other Hatcher Public Services

The librarian who heads the SSR unit attends the regular meetings of the Hatcher public service units. She also serves on standing committees, such as the user education committee. The head of SSR serves as the Hatcher selector and fund manager for general interest periodicals and newspapers. SSR staff members give tours of the unit to new faculty and students and serve at the Hatcher general information desk each fall. The unit also coordinates the ordering and routing of sample issues of new periodical titles. Operationally, the unit, though located within technical services, has been firmly linked to the public service activities of the Hatcher collection.

No formal attempt to measure the impact of these common-sense refinements in service has seemed warranted. The comments of public services staff, faculty, and students have tended to confirm the decisions of the project team concerning, for example, the rearrangement of our unbound periodicals by call number.

Such comments have also indicated directions for further improvement. The function of the unit, for example, is not transparent to new patrons-the stacks where the unbound issues are located are hidden from view by our newspaper processing area. We are also planning, in response to patron requests, a display section for new titles and titles under consideration for purchase.

The changes we have outlined in the organization of our unbound periodical collection have been, for the most part, pragmatic and incremental. In the next few years, we are anticipating far more dramatic changes in service delivery through automation of our check-in routine and the implementation of NOTIS's integrated system. Yet even in an automated environment with auxiliary services such 
as document delivery, accessibility to records and swift access to materials will continue to be important service goals. Our experience with the merger of a public and a technical service serials unit has given us a heightened sensitivity to the impact on patron access of seemingly technical, organizational decisions. We expect that that experience will stand us--and our users--in good stead as we move from ink on paper to full text journals on optical disks. The medium changes, but the end does not.

\section{NOTE}

For a description of the merger process see Carol Holbrook et al. "The Merging of Serials Units: A Case Study," Journal of Academic Librarianship 10:1 (March 1984): 29-32. 